SAND86-8244 $\bullet U C-25$

Unlimited Release

Printed January 1987

\title{
Modeling of Temporal Behavior of Isotopic Exchange Between Gaseous Hydrogen and Palladium Hydride Power
}

C. F. Melius and G. W. Foltz

Piepared by

Sandia National Laboratories

Aibuquerque, New Mexico 87185 and Livermore, California 94550

for the United States Department of Energy

under Contract DE-AC04-76DP00789 
Issued by Sandia National Laboratories, operated for the United States Department of Energy by Sandia Corporation.

NOTICE: This report was prepared as an account of work sponsored by an agency of the United States Government. Neither the United States Government nor any agency thereof, nor any of their employees, nor any of the contractors, subcontractors, or their employees, makes any war. ranty, express or implied, or assumes any legal llability or responsibility for the accuracy, completeness, or usefulness of any information, apparatus, product, or process disclosed, or represents that its use would not infringe privately owned rights. Reference herein to any specific commercial product, process, or service by trade name, trademark, manufacturer, or otherwise, does not necessarily constitute or imply Its endorsement, recommendation, or favoring by the United States Government, any agency thereof or any of their contractors or subconractors. The views and opinions expressed herein do not necessarily state or reflect those of the United States Government, any agency thereof or any of their contractors or subcontractors.

Printed in the Unitted Stales of Amertca

Avallable from

National Technical hiformation Service

5285 Port Royal Road

Springfield, VA 22161

NTS price codes

Microfiche copy: A01 


\section{DISCLAIMER}

This report was prepared as an account of work sponsored by an agency of the United States Government. Neither the United States Government nor any agency Thereof, nor any of their employees, makes any warranty, express or implied, or assumes any legal liability or responsibility for the accuracy, completeness, or usefulness of any information, apparatus, product, or process disclosed, or represents that its use would not infringe privately owned rights. Reference herein to any specific commercial product, process, or service by trade name, trademark, manufacturer, or otherwise does not necessarily constitute or imply its endorsement, recommendation, or favoring by the United States Government or any agency thereof. The views and opinions of authors expressed herein do not necessarily state or reflect those of the United States Government or any agency thereof. 


\section{DISCLAIMER}

Portions of this document may be illegible in electronic image products. Images are produced from the best available original document. 
SAND86-8244

Unlimited Release

Printed January 1987

\title{
MODBLING OF TEMPORAL BBHAVIOR OP ISOTOPIC BXCHANGB BETYBEN GASBOUS HYDROGEN AND PALLADIUH HYDRIDE POUDRR
}

\author{
C. F. Melius \\ Combustion of Energetic Materials Division \\ G. W. Foltz \\ High Temperature Interfaces Division \\ Sandia National Laboratories, Livermore, CA
}

\begin{abstract}
A parametric rate-equation model is described which depicts the time dependent behavior of the isotopic exchange process occurring between the solid and gas phases in gaseous hydrogen (deuterium) flows through packed-powder palladium deuteride (hydride) beds. The exchange mechanism is assumed to be rate-limited by processes taking place on the surface of the powder. The fundamental kinetic parameter of the model is the isotopic exchange probability, $p$, which is the probability that an isotopic exchange event occurs during a collision of a gas phase atom with the surface. Isotope effects between the gas and solid phases are explicitly included in terms of the isotope separation factor, $\alpha$. Results of the model are compared with recent experimental measurements of isotope exchange in the $\beta$-phase hydrogen/ palladium system and, using a literature value of $\alpha=2.4$, a good description of the experimental data is obtained for $p \sim 10^{-7}$. In view of the importance of the isotope effects in the hydrogen/palladium system and the range of $\alpha$ values reported for the $\beta$-phase in the literature, the sensitivity of the model results to a variation in the value of $\alpha$ is examined.
\end{abstract}


ACKNOULBDGEHENTS

The authors wish to thank Prof. W. L. Vorrell, J. O. Noell, and M. L. Koszykowski for useful discussions. 
Model

Rate Equations

Isotopic Exchange Rate

Isotope Exchange Probability 11

Gas Phase Molecular Composition $\quad 12$

Implementation

Results

Discussion

Summary

\section{DISCLAIMER}

This report was prepared as an account of work sponsored by an agency of the United States Government. Neither the United States Government nor any agency thereof, nor any of their employees, makes any warranty, express or implied, or assumes any legal liability or responsibility for the accuracy, completeness, or usefulness of any information, apparatus, product, or process disclosed, or represents that its use would not infringe privately owned rights. Reference herein to any specific commercial product, process, or service by trade name, trademark, manufacturer, or otherwise does not necessarily constitute or imply its endorsement, recommendation, or favoring by the United States Government or any agency thereof. The views and opinions of authors expressed herein do not necessarily state or reflect those of the United States Government or any agency thereof. 


\section{ILLUSTRATIONS}

No. $\quad \underline{\text { Page }}$

1 Composition of gas exiting bed versus time during deuterideto-hydride (D-to-H) exchange process.

2 Composition of gas exiting bed versus time during hydrideto-deuteride (H-to-D) exchange process.

3 Comparison of model prediction of output gas composition for the $\mathrm{H}-$ to-D exchange process using $\mathrm{p}=2.6 \times 10^{-7}$ and $\alpha=2.4$ (solid curves) and using $p=3.7 \times 10^{-7}$ and $\alpha=1.8$ (dashed curves). 


\section{MODELING OF TEMPORAL BBHAVIOR OF ISOTOPIC EXCHANGE BETVEEN GASEOUS HYDROGEN AND PALLADIUM HYDRIDE POVDER}

\section{INTRODUCTION}

Hydrogen isotope exchange between the gas and solid phases is of considerable importance from both a fundamental and technological point of view. Recently, real-time experimental measurements have been made of the isotopic exchange reaction occurring between the solid and gas phases in gaseous hydrogen (deuterium) flows through packed-powder beds of $\beta$-phase palladium deuteride (hydride) (1). In those experiments, the isotopic composition of the gas exiting from the bed was determined as a function of time during the exchange process. For the conditions used, it was observed that there exists a significant difference in temporal exchange efficiency between gaseous hydrogen flowing through $\beta$-phase palladium deuteride powder and the reverse process of gaseous deuterium flowing through $\beta$-phase palladium hydride powder. The purpose of this report is to describe a parametric rate equation model which portrays the time dependent behavior of the isotopic exchange process in gas flows through packed-powder beds and to present results of this model obtained for the hydrogen/palladium system under the experimental conditions of Ref. (1).

MODEL

\section{Rate Equations}

The description of the time behavior of the exchange process in gas flows through packed-powder beds is cast in terms of a set of parametric rate equations in which both the effects of isotopic exchange and gas flow through the bed are included. For specificity, the model is described for the case in which deuterium is initially sorbed into the powder and hydrogen gas flowed into the bed. However, keeping in mind the assumptions made, the rate equations are generally applicable to a variety of situations.

While hydrogen and deuterium are present both as atoms (in the solid) and molecules (in the gas), the rate equations are written solely in terms of atomic densities of $H$ and $D$. Letting $n_{S_{D}}, n_{s_{H}}, n_{g_{D}}$, and $n_{g_{H}}$ represent the densities in moles of deuterium and hydrogen atoms per unit volume in the solid and gas phases, respectively, four coupled rate equations (one for each phase and isotopic species) describing the overall macroscopic aspects of the exchange process may be written as 


$$
\begin{aligned}
\text { Solid: } & \partial \mathrm{n}_{\mathrm{s}_{\mathrm{D}}} / \partial \mathrm{t}=-\mathrm{R} \\
& \partial \mathrm{n}_{\mathrm{s}_{\mathrm{H}}} / \partial \mathrm{t}=\mathrm{R} \\
\text { Gas: } & \partial \mathrm{n}_{\mathrm{g}_{\mathrm{D}}} / \partial \mathrm{t}=(1-\phi) R / \phi-\partial\left(\mathrm{n}_{\mathrm{g}_{\mathrm{D}}} \mathrm{v}_{\mathrm{f}}\right) / \partial \mathrm{x} \\
\partial \mathrm{n}_{\mathrm{g}_{\mathrm{H}}} / \partial \mathrm{t} & =-(1-\phi) R / \phi-\partial\left(\mathrm{n}_{\mathrm{g}_{\mathrm{H}}} \mathrm{v}_{\mathrm{f}}\right) / \partial \mathrm{x} .
\end{aligned}
$$

Eqns. (1a) and (1b) simply define R, the isotopic exchange rate; Eqn. (1a) describes the loss rate of the initially sorbed isotope, deuterium, from the solid into the gas due to the exchange interaction while Eqn. (1b) equates this deuterium loss rate to the rate of gain by the solid of hydrogen from the gas. The net sorption of gas during the exchange is, therefore, assumed to be zero. Eqns. (2a) and (2b) give the time rate of change of the gas phase deuterium and hydrogen concentrations. The first term in Eqn. (2a) reflects the deuterium loss from the solid as the appearance of that isotope in the gas phase. The factor $(1-\phi) / \phi$ in this term, where $\phi$ is the porosity of the bed, is the solid-to-void volume ratio of the bed and.adjusts for the difference between solid volume and void volume in the bed. The second term in Eqn. (2a) accounts for the fact that the gas is flowing through the bed and comes from the fluid dynamic equation of continuity written for onedimensional flow where $x$ is measured axially through the bed and $v_{f}$ is the flow velocity along that dimension. Eqn. (2b) for gas phase hydrogen is identical to Eqn. (2a) except for the minus sign in front of the $R$ term which depicts the loss of $\mathrm{H}$ atoms from the gas to the solid.

\section{Isotopic Exchange Rate}

In order to specify the nature of the isotope exchange rate, $R$, it is necessary to examine the microscopic aspects of the exchange process. The overall exchange reaction is comprised of several more elementary processes involving the hydrogen and deuterium atoms and molecules which can be conveniently separated into three groups: processes occurring within the solid, gas phase processes occurring in the flowstream, and surface processes. The solid phase processes can include, for example, solid diffusion, grain boundary diffusion, and trapping, which together determine the transport of sorbed hydrogen and deuterium atoms in the solid. The gas phase processes can include diffusion, turbulent transport, and boundary layer processes, which together govern the motion of the gas molecules between the flowstream and the particle surface. Finally, the surface processes can include the various adsorption and desorption processes, and movement of species on the surface, which together constitute the chemical exchange mechanism itself. Previous work (2) has indicated that, for the experimental conditions used in Ref. (1) in the hydrogen/palladium system, the solid and gas phase processes occur on a time scale which is short compared to that of the surface processes and, therefore, that the group of surface interactions constitutes the rate-limiting step of the overall exchange reaction. Consequently, in the evaluation of $\mathrm{R}$, both solid and gas phase processes are assumed to proceed with sufficient rapidity so as to have a negligible effect on the exchange 
kinetics; the main modeling effort is directed at the surface processes. The ultimate validity of such a surface rate-limited model is, of course, determined by comparison with experiment.

It is not necessary to fully specify a surface reaction mechanism in order to give a description of the reaction kinetics at the surface. A set of exchange reactions may be written (for zero net gas sorption during the exchange) as

$$
\begin{aligned}
& \mathrm{D}_{2}+\mathrm{H}_{\mathrm{s}} \underset{\mathrm{k}_{-1}}{\stackrel{\mathrm{k}_{1}}{\rightleftarrows}} \mathrm{HD}+\mathrm{D}_{\mathrm{s}} \\
& \mathrm{HD}+\mathrm{H}_{\mathrm{s}} \underset{\mathrm{k}_{-2}}{\stackrel{\mathrm{k}_{2}}{\rightleftarrows}} \mathrm{H}_{2}+\mathrm{D}_{\mathrm{s}},
\end{aligned}
$$

where $D_{2}, H D$, and $H_{2}$ are gas phase molecules above the surface while $H_{s}$ and D represent hydrogen and deuterium atoms, respectively, bound to the solid. ${ }^{1}$ With the rate constants for the reactions denoted as indicated by the $k_{i}$ 's in Eqns. ( $3 a$ ) and (3b), the rate equation for the concentration of $D_{s}$ is

$$
\partial\left[D_{s}\right] / \partial t=k_{1}\left[D_{2}\right]\left[H_{s}\right]+k_{2}[H D]\left[H_{s}\right]-k_{-1}[H D]\left[D_{s}\right]-k_{-2}\left[H_{2}\right]\left[D_{s}\right] \text {, }
$$

where the square brackets indicate concentrations of the species enclosed. Assuming that the following relationships hold between the $k_{i}{ }^{\prime} s$,

$$
\begin{aligned}
& k_{2}=1 / 2 k_{1} \\
& k_{-1}=\alpha k_{2}=1 / 2 \alpha k_{1} \\
& k_{-2}=\alpha k_{1},
\end{aligned}
$$

1 Eqns. (3a) and (3b) describe what will be called a "single-site" exchange process in which only one of the atoms of an incident gas phase molecule is exchanged with an atom bound to the solid during a gas/surface collision. A "two-site" process is also possible (Ref. 3) in which both atoms of the incident molecule are exchanged with atoms from the solid. Reactions for this latter process are:

$$
\begin{aligned}
& \mathrm{D}_{2}+\mathrm{H}_{\mathrm{s}}+\mathrm{H}_{\mathrm{s}} \rightleftarrows \mathrm{H}_{2}+\mathrm{D}_{\mathrm{s}}+\mathrm{D}_{\mathrm{s}} \\
& \mathrm{D}_{2}+\mathrm{H}_{\mathrm{s}}+\mathrm{D}_{\mathrm{s}} \rightleftarrows \mathrm{HD}_{\mathrm{D}}+\mathrm{D}_{\mathrm{s}}+\mathrm{D}_{\mathrm{s}} \\
& \mathrm{HD}+\mathrm{H}_{\mathrm{s}}+\mathrm{H}_{\mathrm{s}} \rightleftarrows \mathrm{H}_{2}+\mathrm{H}_{\mathrm{s}}+\mathrm{D}_{\mathrm{s}}
\end{aligned}
$$

Use of these two-site reactions in evaluating the isotope exchange rate, $R$, has not provided as good a level of agreement between the model results and the experimental data as has the single-site process of Eqns. (3a) and (3b). 
where the factor of $t_{2}$ in Eqn. (5a) is obtained from statistical considerations and where a gas-to-solid-phase isotope effect is explicitly taken into account by the use of the isotope separation factor, $\alpha$, Eqn. (4) can be expressed as

$$
\partial\left[D_{s}\right] / \partial t=k_{1}\left\{\left(\left[D_{2}\right]+H_{2}[H D]\right)\left[H_{s}\right]-\alpha\left(\left[H_{2}\right]+H_{2}[H D]\right)\left[D_{s}\right]\right\} .
$$

Letting $f_{g_{H}}, f_{g_{D}}, f_{s_{H}}$, and $f_{s_{D}}$ equal the mole fractions in the gas and solid phases of $H$ and $D$, respectively, such that

$$
\begin{aligned}
& \mathbf{f}_{\mathbf{g}_{\mathrm{H}}}=\left(\left[\mathrm{H}_{2}\right]+\mathrm{H}_{2}[\mathrm{HD}]\right) /\left(\left[\mathrm{H}_{2}\right]+[\mathrm{HD}]+\left[\mathrm{D}_{2}\right]\right) \\
& \mathbf{f}_{\mathbf{s}_{\mathrm{H}}}=\left[\mathrm{H}_{\mathbf{s}}\right] /\left(\left[\mathrm{H}_{\mathbf{s}}\right]+\left[\mathrm{D}_{\mathbf{s}}\right]\right)
\end{aligned}
$$

and similarly for deuterium, and letting $k$ be the averaged or isotope independent rate constant $\left[\bar{k}=\left(k_{1} k_{-2}\right)^{1 / 2}\right]$, Eqn. (6) can be re-written as

$$
\partial\left[D_{s}\right] / \partial t=k\left(\left[H_{2}\right]+[H D]+\left[D_{2}\right]\right)\left(\left[H_{s}\right]+\left[D_{s}\right]\right)\left\{(\alpha)^{-1 / 2} f_{g_{D}} f_{s_{H}}-(\alpha)^{1 / 2} f_{g_{H}} f_{B_{D}}\right\} .
$$

Up to this point the exact nature of both the $k_{i}^{\prime} s$ and the species concentrations has been left unspecified. The system has simply been divided into a gas phase region, a solid phase region, and an interfacial region separating the gas and the solid. Identification of the species concentrations as surface densities, as is pertinent for a strict surface reaction, may be accomplished in Eqn. (7) by regarding $\left(\left[\mathrm{H}_{s}\right]+\left[\mathrm{D}_{\mathrm{s}}\right]\right)$ as the surface density, $\mathrm{N}_{\text {surf }}$, of hydrogen and deuterium atoms bound to the solid, i.e.,

$$
N_{s u r f}=\left(\left[H_{s}\right]+\left[D_{s}\right]\right),
$$

and by associating $\left(\left[\mathrm{H}_{2}\right]+[\mathrm{HD}]+\left[\mathrm{D}_{2}\right]\right)$ with the flux or impingement rate, $\mathrm{I}$, on to the surface of all gas phase species. I can be expressed as

$$
I=k\left(n_{g_{D}}+n_{g_{H}}\right)(8 R T / \pi M)^{1 / 2},
$$

where $(8 R T / \pi M)^{1 / 2}$ is the thermal velocity, $v_{t}$, of a gas molecule of mass $M$ at temperature $T$ and $R$ is the gas constant. Note that, as a result of the assumption that the transport processes in the gas and solid phases are rapid compared to the interfacial processes, this correspondence of species concentrations with surface densities does not create any ambiguity in the definitions of the mole fractions, $f_{i}^{\prime} s$. Under this assumption, the [H]/[D] ratio in the near-surface gas phase is proportional to the [H]/[D] ratio out in the free-stream gas and, similarly, the [H]/[D] ratio on the solid surface is proportional to that ratio deep in the solid. Thus, from Eqns. (1), (7), 
(8), and (9)

$$
R=4 k k\left(n_{g_{D}}+n_{g_{H}}\right)(8 R T / \pi M)^{4 / 2} S_{O} N_{s u r f}\left[(\alpha)^{1 / 2} f_{g_{H}} f_{s_{D}}-(\alpha)^{-4 / 2} f_{g_{D}} f_{s_{H}}\right] \text {. }
$$

The constant of proportionality, $k$, is the isotopic exchange coefficient and $S_{0}$ is the specific surface of the powder (powder surface-area-to-solidvolume). The inclusion of $\mathrm{S}_{\text {in }}$ iqn. (10) converts the exchange rate from moles per second per unit solid surface area to moles per second per unit solid volume as required by Eqns. (1) and (2). The values of the $f_{i}$ 's obtained from volume species densities are used in the model computations and the proportionality constants mentioned above concerning the [H]/[D] ratios are absorbed into the isotopic exchange coefficient.

With $\mathrm{R}$ given by Eqn. (10), Eqns. (1a) and (1b) indicate that deuterium is lost from and hydrogen gained by the solid when $(\alpha)^{-1 / 2}$ times the product of the hydrogen impingement rate [given by $4 /\left(n_{g_{D}}+n_{g_{H}}\right) v_{t} f_{g_{H}}$ ] and the deuterium surface density [given by $N_{s u r f} f_{s_{D}}$ ] is greater than $(\alpha)^{-1 / 2}$ times the product of the deuterium impingement rate [given by $1 /\left(n_{g_{D}}+n_{g_{H}}\right) v_{t} f_{g_{D}}$ ] and the hydrogen surface density [given by $\mathrm{N}_{s u r f} \mathrm{f}_{\mathrm{s}_{\mathrm{H}}}$ ]. If this inequality is reversed then hydrogen is lost from and deuterium gained by the solid. At equilibrium $\left\{(\alpha)^{1 / 2} f_{g_{H}} f_{s_{D}}-(\alpha)^{-1 / 2} f_{g_{D}} f_{B_{H}}\right\}=0$ and

$$
\alpha=\left(f_{B_{H}} / f_{g_{H}}\right) /\left(f_{B_{D}} / f_{g_{D}}\right)=\left(f_{g_{D}} / f_{g_{H}}\right) /\left(f_{B_{D}} / f_{s_{H}}\right)
$$

as required according to the standard definition of the isotope separation factor [see, for example, Ref. (4)]. Note that the presence of $\alpha$ in general removes the symmetry otherwise present between the $f_{i}$ concentration terms in Eqn. (10) and, depending upon its value $(\neq 1)$, drives the equilibrium of the exchange reaction away from the condition in which, for each isotope, the gas and solid phase mole fractions are equal. In the case of the H/D/Pd system, $\alpha>1$, indicating that hydrogen has a greater affinity for the metal than deuterium relative to the gas phase. Therefore, the direction of the exchange reaction which results in hydride formation is favored over the reverse direction which leads to the deuteride. This directional bias is clearly evident in the mathematical structure of Eqn. (10). ${ }^{2}$

Isotopic Exchange Probability

From Eqns. (1) and (10) it is seen that the isotopic exchange

2 For no isotope effect, $\alpha=1$ and the symmetry of the concentration terms is regained. 
coefficient, $k$, has units of $\mathrm{cm}^{2} / \mathrm{mole}$. It is therefore useful to express $k$ as

$$
k=p \sigma,
$$

where $\sigma$ is defined as the surface area occupied by a mole of adsorbed $H$ or $D$ atoms such that $\sigma=\left(\mathrm{N}_{\text {surf }}\right)^{-1}$. The quantity $\mathrm{p}$ can then be interpreted as the probability that an isotopic exchange event occurs during a collision of a gas phase atom with the surface. Thus, $p$ is called the isotopic exchange probability and it constitutes the fundamental kinetic parameter of the model. The temperature dependence of $p$ can be included explicitly via an Arrhenius equation

$$
p=p_{0} \exp \left(-E_{a} / R T\right)
$$

where $E_{a}$ is an activation energy for the exchange reaction.

\section{Gas Phase Molecular Composition}

At any location in the bed and at any time, conversion of the gas phase atomic densities of $H$ and $D$ to molecular densities of $H_{2}, D_{2}$, and $H D$ is accomplished assuming that equilibrium between the isotopic molecular species in the gas holds at all points in space and time within the bed. The process which establishes this equilibrium anongst the gas phase species can be described by the reaction

$$
\mathrm{H}_{2}+\mathrm{D}_{2} \rightleftarrows 2 \mathrm{HD} \text {. }
$$

The equilibrium constant, $K_{e q}$, for this reaction is given in Ref. (5) as

$$
\log K_{e q}=-(155 / 4.57 T)+0.6276
$$

and has a value of 3.267 at $299 \mathrm{~K}$. The molecular mole fractions, $\mathrm{f}_{\mathrm{g}_{\mathrm{HD}}}, \mathrm{f}_{\mathrm{g}_{\mathrm{H}_{2}}}$, and $\mathrm{f}_{{ }_{\mathrm{g}_{2}}}$, are given in terms of the atomic mole fractions, $f_{g_{H}}$ and $f_{g_{D}}$, and K.g by

$$
\begin{aligned}
& f_{g_{H D}}=-\left[K_{e q} /\left(4-K_{e q}\right)\right]+\left[2 /\left(4-K_{e q}\right)\right]\left\{\left(K_{e q}{ }^{2} / 4\right)+4 K_{e q}\left[1-\left(K_{e q} / 4\right)\right] f_{g_{H}} f_{g_{D}}\right]^{1 / 2} \\
& f_{g_{H_{2}}}=f_{g_{H}}-1 / 2 f_{g_{H D}} \\
& \mathrm{f}_{\mathrm{g}_{\mathrm{D}_{2}}}=\mathrm{f}_{\mathrm{g}_{\mathrm{D}}}-{ }^{1 / 2 \mathrm{f}_{\mathrm{g}_{\mathrm{HD}}}} \text {. }
\end{aligned}
$$




\section{Implementation}

In the exchange experiments conducted on the hydrogen/palladium system (1), a well-characterized, spherical particle, powder bed of $\beta$-phase palladium deuteride (hydride) was prepared. At $t=0$ a hydrogen (deuterium) gas flow through the bed was established by setting $P_{\text {in }}>P_{\text {out }}$ where $P_{\text {in }}$ and $P_{\text {ou }}$ are the gas pressures at the input and output ends, respectively, of the bed. Measurements of the gas pressures, gas flow rate, $Q$, and isotopic composition of the gas (partial pressures of $\mathrm{H}_{2}, \mathrm{D}_{2}$, and HD) exiting from the powder bed were performed in real time during the exchange process.

In applying the model to this experimental situation, the set of coupled partial differential equations, Eqns. (1) and (2) with $R$ given by Eqns. (10) and (12), are solved for $n_{s}(x, t)$ and $n_{g}(x, t)$ for $H$ and $D$ using a stiff ODE integrater. The gas phase component, $h_{\tau}(x, t)$, is, in turn, converted from atomic to molecular composition (as a function of $x$ and $t$ ) using Eqns. (15). The time-resolved molecular composition of the gas (in terms of partial pressures) at the output end of the bed is directly compared with the experimental data. The isotopic exchange probability, $p$, is regarded as a freely-varying parameter in the model calculations and is evaluated by fitting the model results to the experimental data. Details of the fitting procedure are given in the Appendix.

Initial conditions for the calculations are provided by the experimental values of temperature measured at the start of each experiment $(299 \mathrm{~K})$, gas pressure $\left(\mathrm{P}_{i^{n}} \sim 1050-1200\right.$ Torr $^{3} \mathrm{P}_{\text {out }} \sim 750-760$ Torr $)$, and initial palladium deuteride (hydride) stoichiometry $\left(\mathrm{PdD}_{0.61}, \mathrm{PdH}_{0.65}\right)$. The value of $\phi(=0.31)$ is taken from the experiment and a geometric value for $S\left[\left[(6 / d) \simeq 505 \mathrm{~cm}^{-1}\right.\right.$ where $d$ is the powder particle diameter) is assumed. ${ }^{4}$ The gas flow velocity, $v_{f}$, which appears in the (one-dimensional) flow terms in Eqns. (2a) and (2b) is the pore velocity in the bed and is calculated from

$$
v_{f}=(K / \mu \phi) \Delta P / \Delta x,
$$

where $K$ is the permeability of the bed, $\mu$ is the gas viscosity, and $\Delta P$ is the pressure drop along an axial increment, $\Delta x$, of the bed. This expression is obtained from applying the Dupuit-Forchheimer assumption to Darcy's law (6). [The applicability of Darcy's law to the experimental flow regime was

3 In fact, the experimentally observed variation of $P_{\text {in }}$ with time is fit with a cubic polynomial which is used to provide $P_{\text {in }}$ as a function of time for the calculation.

4 The values of $\phi$ and $S_{\circ}$ given above include the effects of the palladium expansion which occurs upon deuteriding (hydriding) the powder. Furthermore, the geometric value for $S$ was found to be consistent with the pressure/flow characteristics of the powder bed. See Ref. (1) for details. 
demonstrated in Ref. (1).] The gas viscosity changes with the changing gas composition during the exchange process. Using the gas phase molecular composition at each location and time in the bed, a value of $\mu(x, t)$ for the mixed species gas is obtained from the Wilke formula (7). While values of $\mathrm{k}$, spatially averaged over the bed, were measured in Ref. (1), the calculated gas composition is compared to experimental data obtained at the center of the flow channel (from Raman light scattering out of a laser beam focused on the channel axis). Since potential radial dependences of the flow and exchange process are ignored in the calculations, use of an experimentally measured value of $\mathrm{K}$ is questionable. Furthermore, the measured values of $\mathrm{K}$ for the hydrided and deuterided beds were observed to be somewhat different. Consequently, $K$ used in Eqn. (16) is allowed to vary while fitting the experimental data. Comparison of the $K$ value obtained from the fit to the measured values shows good agreement (see Appendix) and indicates that reasonable accuracy is at tained by the one-dimensional flow features of the model. It is emphasized that the two parameters, $p$ and $K$, are, to a large extent, uncoupled and each can be varied independently in obtaining a fit to the experimental data (see Appendix). The molecular mass, $M$, used to obtain $v_{t}$ in Eqn. (9) is fixed at the value of 3 amu (the simple average molecular mass of the gas).

Several studies of the isotope separation factor, $\alpha$, for the $\beta$-phase $\mathrm{H} / \mathrm{D} / \mathrm{Pd}$ system have been reported and $\alpha$ is found to be dependent both on temperature and to a lesser degree on the H/D composition ratio. Measurements on palladium black for H/D $\sim 1$ have yielded room temperature values of $\alpha$ ranging from about 1.8 to 2.5 (8-11). Thermodynamic calculation of $\alpha$ using measurements of the vibrational frequencies of $H$ and $D$ in the lattice gives a value of $\sim 2.3$ at room temperature (12). While equilibrium values of $\alpha$ are of ten measured, use of such values in the analysis of dynamical situations, such as the experiments of Ref. (1), may not be justified. A value of $\alpha=$ 2.4 from Ref. (9) is used to obtain the model results presented in this work (see Results). However, as a consequence of the uncertainties just discussed, the sensitivity of the model results to variations in $\alpha$ is examined (see Discussion). The variation in $\alpha$ due to changes in the $\mathrm{H} / \mathrm{D}$ ratio of the overall system $[\sim 20 \%(11)]$ is also incorporated in the model. ${ }^{5}$

\section{RESULTS}

In Figs. 1 and 2 the data of two types of exchange experiments (discrete points) are reproduced from Ref. (1). The data in Fig. 1 pertain to an

5 In addition, the contribution to isotope separation by adsorption of hydrogen and deuterium on the surface, as compared to absorption into the solid, [see, for example, Ref. (12)] are expected to be negligible in the present application due to the small specific surface of the powder used in the work of Ref. (1). 


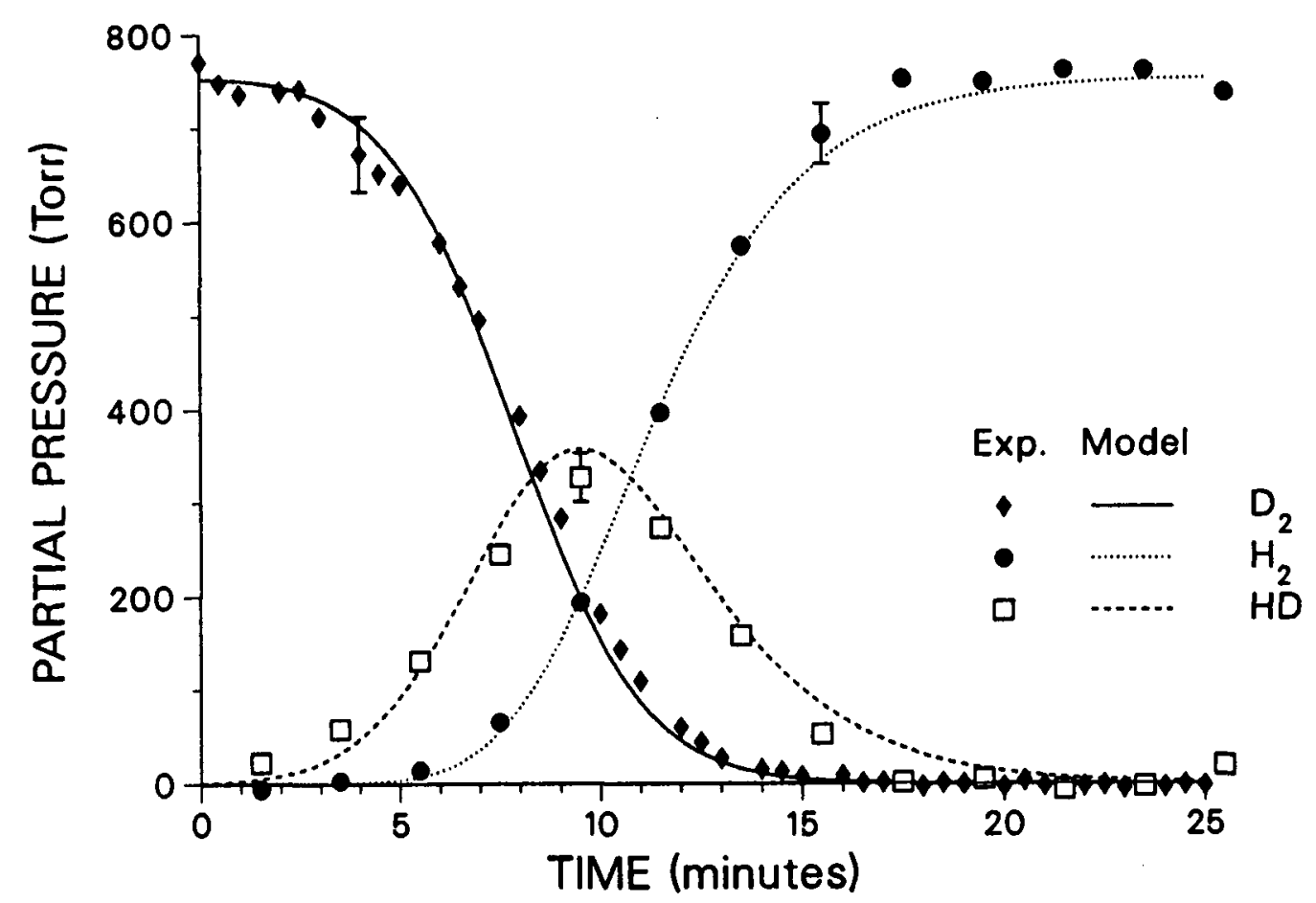

Figure 1. Composition of gas exiting bed versus time during deuteride-tohydride (D-to-H) exchange process.

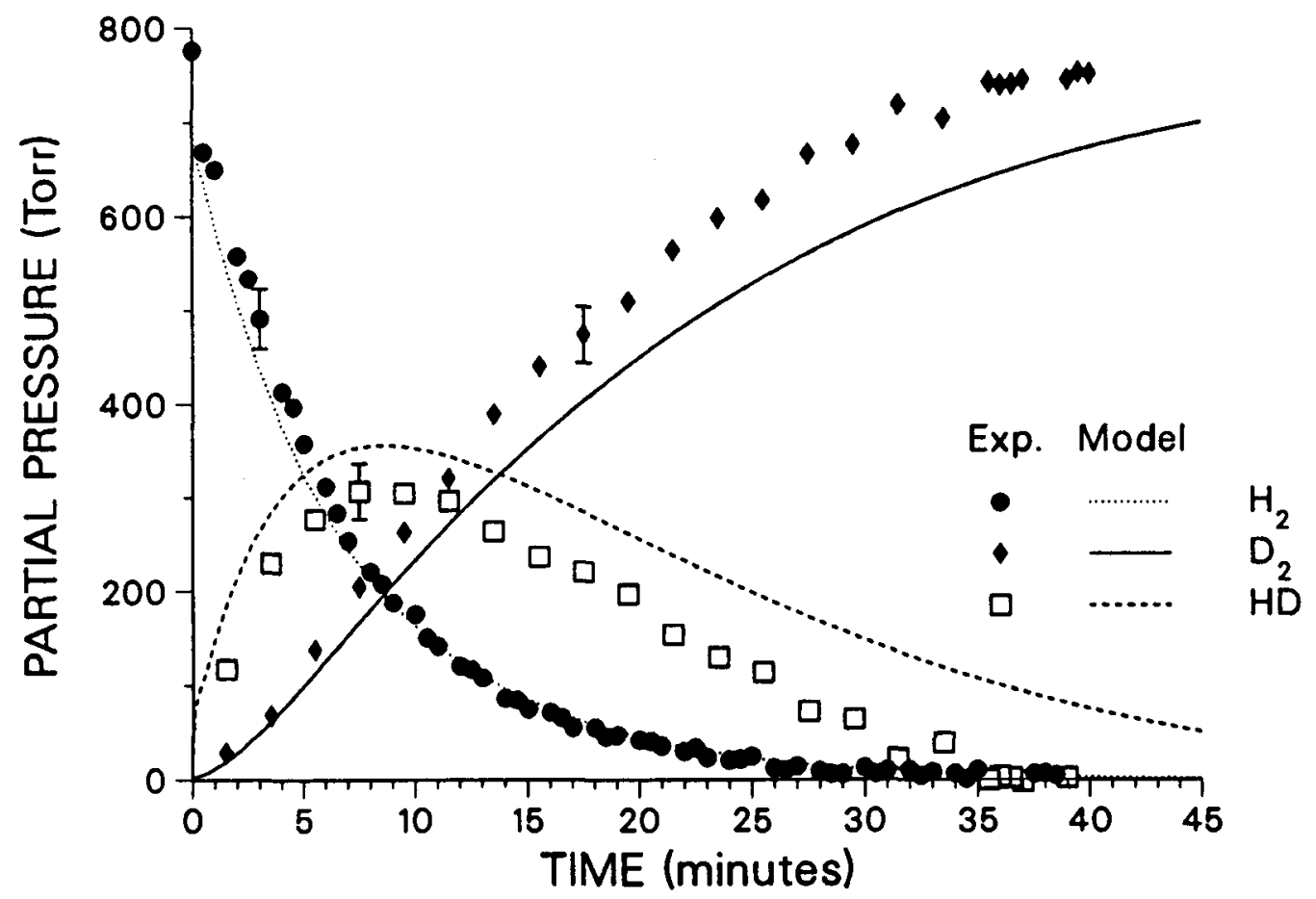

Figure 2. Composition of gas exiting bed versus time during hydride-todeuteride (H-to-D) exchange process. 
experiment in which deuterium was initially sorbed into the Pd powder and hydrogen was flowed through the bed (referred to as a D-to-H exchange), while Fig. 2 depicts the results for the reverse process, an $\mathrm{H}-\mathrm{to}_{\mathrm{O}} \mathrm{D}$ exchange, obtained under conditions reasonably similar to those used in the D-to-H process. Note the longer time scale used in Fig. 2. In each case the partial pressures of $\mathrm{D}_{2}$ and $\mathrm{H}_{2}$ in the gas exiting from the bed (solid diamonds and circles, respectively) were measured as a function of time during the run and the partial pressure of HD (open squares) versus time obtained by subtraction from the measured total output pressure. For specific details on the experimental conditions used, see Ref. (1). The error bars given on several of the experimental data points indicate the random uncertainty $( \pm 2$ standard deviations) in the partial pressure determinations.

Also shown in Figs. 1 and 2 are the results of the model calculations (curves) for each experiment. The curves in Fig. 1 for the D-to-H exchange were obtained by fitting the experimental data using a fixed value of 2.4 for $\alpha$ from Ref. (9) and allowing $p$ to vary. The best fit in this case resulted for $p=2.6 \times 10^{-7}$. Using this value of $p$, along with $\alpha=2.4$, the model was then applied to the conditions of the H-to-D experiment and used to predict the output gas composition as a function of time. The results of this prediction are shown in Fig. 2. (The value of $K$ obtained from the model fit of the D-to-H data was used in the model prediction of the H-to-D experiment.)

\section{DISCUSSION}

As discussed in Ref. (1), the experimental data shown in Figs. 1 and 2 indicate that there is a significant difference between the $\mathrm{D}-$ to- $\mathrm{H}$ and $\mathrm{H}-\mathrm{to}-\mathrm{D}$ processes. The $\mathrm{H}-$ to-D exchange is temporally less efficient than the $\mathrm{D}-\mathrm{to}-\mathrm{H}$ conversion. The fact that good agreement with the data of both experiments can be obtained from the model using the same value of $p$ (and the temperature measured at the start of each experiment, see discussion below) is significant, in that the difference in efficiency between runs is therefore due primarily to the isotope effect. As discussed earlier, this effect, represented by the factor $\alpha$ in the model, favors the D-to-H exchange process while hindering the reverse process.

It is seen from Figs. 1 and 2 that good agreement between the model results and the experimental data can be achieved using an $\alpha$ value $(=2.4)$ reported in the literature [Ref. (9)]. In order to ascertain whe ther or not this agreement can be improved, a model fit to both the D-to-H and the H-to-D exchange data simultaneously while permitting $\alpha$ as well as $p$ to vary, was investigated. It was concluded from this exercise that little improvement in the model results is possible; the curves in Figs. 1 and 2 essentially represent the optimum results. Furthermore, as an indication of the sensitivity of the model results to the use of different values of $\alpha$, a second fit of the D-to-H data (Fig. 1) using $\alpha=1.8$ [from Ref. (8)] was undertaken. For $p=3.7 \times 10^{-7}$, this second $\mathrm{fit}$ is as good as the one shown in Fig. 1. Using this value of $p$ and 1.8 for $\alpha$, a second prediction of the H-to-D data 


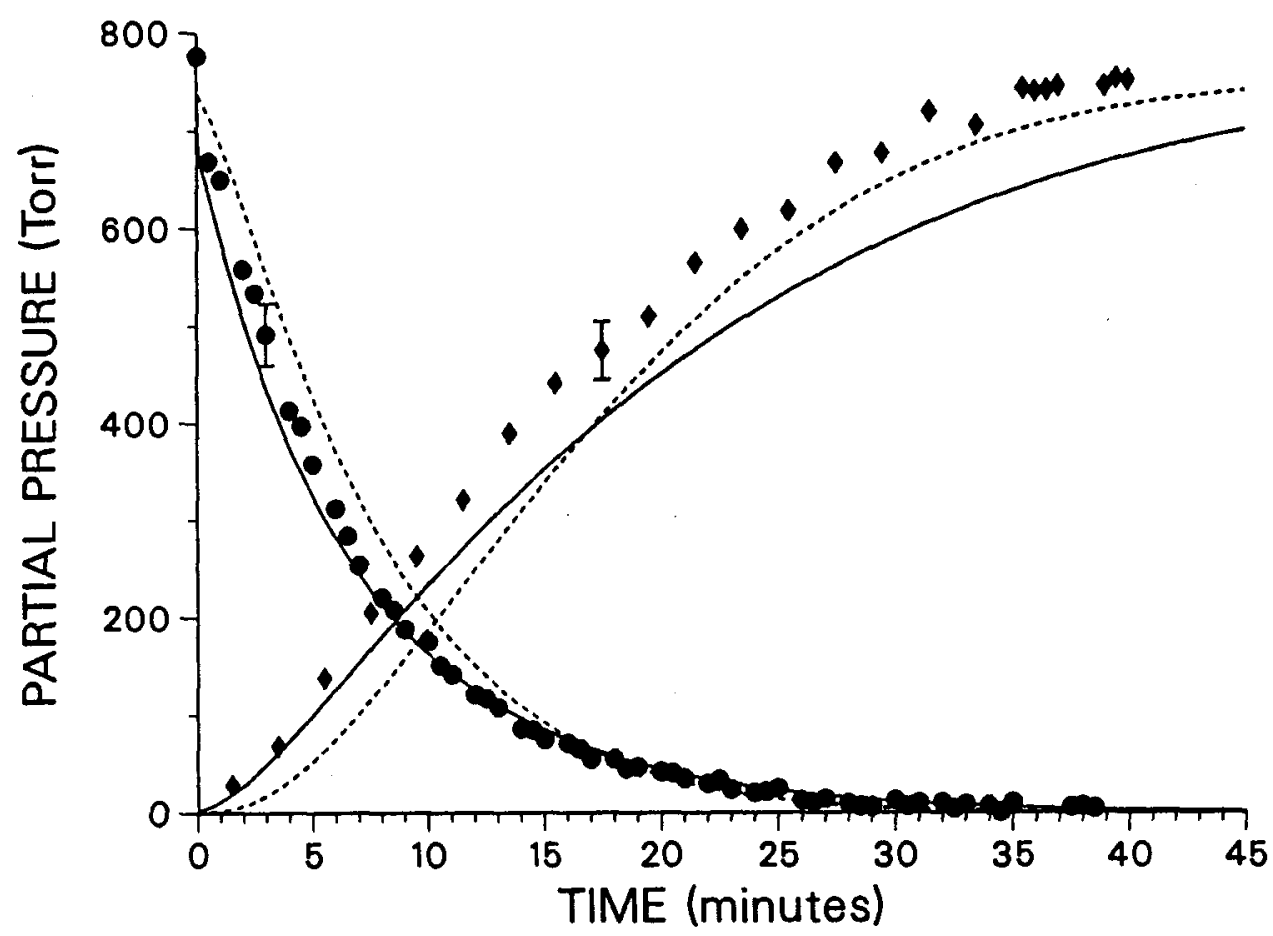

Figure 3. Comparison of model prediction of output gas composition for the $H-$ to- $D$ exchange process using $p=2.6 \times 10^{-7}$ and $\alpha=2.4$ (solid curves) and using $\mathrm{p}=3.7 \times 10^{-7}$ and $\alpha=1.8$ (dashed curves). 
(Fig. 2) was made. The results of this calculation are shown (dashed curves) in Fig. 3, along with the previous prediction using $\alpha=2.4$ and $p=2.6 \times 10^{-7}$ (solid curves) and the experimental data. For clarity, only the $\mathrm{H}_{2}$ and $\mathrm{D}_{2}$ partial pressure results are shown. It is felt that the use of $\alpha=2.4$ and $p=2.6 \times 10^{-7}$ yields better agreement with the experimental data.

Several points should be made here based on the results discussed in the last paragraph. By appropriately varying the values of $p$ and $\alpha$ relative to each other, 1 is possible to maintain the same quality fit of the D-to-H data as shown in Fig. 1 over a range of $p$ and $\alpha$ combinations. On the other hand, the quality of the model prediction for the H-to-D exchange run is not improved over that shown in Fig. 2 when combinations of $p$ and $\alpha$ other than $\alpha=2.4$ and $p=2.6 \times 10^{-7}$ are used. In fact, it is not possible to even independently fit the $B-t o-D$ exchange data with the same degree of agreement as is obtained in the fit of the D-to-H data shown in Fig. 1. This inability to fit the H-to-D data to the same level of agreement as is possible for the D-to-H data results from the difference between the two types of exchange experiments in the nature of the isotopic composition of the gas exiting from the bed. Recall that it is assumed in the model that the isotopic composition of the gas in the bed is in equilibrium as expressed by Eqns. (15) with

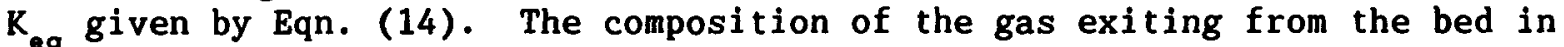
the $\mathrm{D}$-to-H exchange run (Fig. 1) reflects this equilibrium mixture reasonably well. However, the H-to-D data (Fig. 2) shows a noticeable difference. Although the reason for this difference has yet to be conclusively demonstrated, it is not felt that it results from a failure of the gas to achieve isotopic equilibrium. Instead, the possibility of channeling or by-pass gas flow in the H-to-D exchange run as a result of differential powder volume expansion between the hydride and the deuteride is being considered [see discussion in Ref. (1) on bed permeabilityl. Because of this possibility, agreement between the model results and the experimental data at early times during the $\mathrm{H}-$ to-D exchange process is considered more important than at later times.

It was noted in Ref. (1) that the experimental conditions of pressure and temperature are chosen such that the powder remained in the $\beta$-phase during the isotope exchange process and several reasons were given for the importance of this single phase operation. (a) The net amount of gas which is sorbed (desorbed) by the powder over the course of the exchange is small and, thus, the role that this net sorption (desorption) process plays in the overall gas-solid interaction is minimized. (b) The change in powder volume in going from the hydride to the deuteride or vice-versa is expected to be small and therefore the variation in the bed permeability should be small. (c) The types of solid-state diffusion involved are restricted to those which occur in the $\beta$-phase. These three features of single phase operation are directly reflected in the model since (a) it is assumed in the model that the amount of the isotope leaving the powder equals the amount of the other isotope entering the powder, i.e., that the net sorption (desorption) process is zero, (b) a constant bed permeability is used in the model, and (c) the assumption in the model that solid-state diffusion processes are fast is limited to the B-phase solid.

As discussed in Ref. (1), there are several effects that occur during 
the course of the exchange process (partly due to the exchange itself and partly due to other factors) which can cause the temperature of the bed to change from the value measured at the start of the experiment. Heat is released in the D-to-H process while it is absorbed in the H-to-D conversion. Although this heat transfer is not expected (1) to result in a large temperature change under the experimental conditions used, it is important to examine the impact that such a temperature change has on the exchange process. According to the model presented here, the temperature dependence of the process manifests itself in (a) the Arrhenius term in p, (b) $\alpha(\log \alpha$ is inversely proportional to $T$ ), (c) $K_{e q},(d) v_{t},(e) \mu$, and ( $f$ ) the equation of state of the gas. This rather involved temperature dependence includes, for example, compensating temperature variations in $p$ and $\alpha$, (increasing $T$ increases $p$ while $\alpha$ decreases) which mitigates the effect of a temperature change on the direction of the exchange reaction which produces the hydride. Carrying the analysis of temperature effects further is, however, complicated by the uncertainty in both the value of the exchange activation energy, $E_{a}$, in $p$, and the magnitude of the temperature variation of $\alpha$. The temperature used in the model calculations presented here is the value measured at the start of each experiment (1). The success of the model in providing a fit to the D-to-H exchange data (in which local heating is expected) and a good prediction of the H-to-D data (local cooling expected), all with the same values of $p, \alpha$, and temperature $(299 \mathrm{~K})$, indicates that the heat changes occurring in the bed do not greatly influence the exchange process for the experimental conditions used.

As stated earlier, the geometric specific surface value of the hydrided (deuterided) powder is used here. In this case, $p$ is interpreted as the isotopic exchange probability averaged over all surface conditions present and the value of $p$ will certainly be material dependent. Alternatively, it would be possible to use an "active-site" specific surface value where only the powder surface area encompassing active sites is included. The isotopic exchange probability, $p$, would then be a measure of the activity of the "active" sites of the powder surface and would most likely still be a function of the material used.

Independent model fits of data from additional experiments conducted under similar conditions yield values of $p$ which agree to within about a factor of two. Aside from the effects on $p$ caused by the approximations made in implementing the model, the accuracy of the value of $p$ obtained is, of course, directly related to the accuracy of the values of the various parameters, such as the specific surface, $S_{0}$, used in the model. The problems involved in connection with this latter issue are somewhat alleviated if only relative values of $p$ are desired.

Comparison of the (material-dependent) values of $p$ obtained in this work with equivalent quantities derived from the results of work previously reported in the literature is complicated by the variety of conditions, methods, and kinetic parameters used and, in some cases, by the lack of experimental detail reported. However, calculation of an isotopic exchange probability from the isotopic exchange rate constants given by Andreev et al. $(13,14)$ yields a value of $\sim 10^{-8}$ which, considering the various uncertainties, is in reasonable agreement with the value obtained in this work. 


\section{SUMMARY}

A parametric rate equation model is described which depicts the time dependent behavior of the isotopic exchange process occurring between the solid and gas phases in gaseous hydrogen (deuterium) flows through packedpowder palladium deuteride (hydride) beds. Solution of the model equations under appropriate boundary conditions yields a time history of the exchange process (i.e., the hydrogen isotope composition in both the gas and the solid) anywhere in the bed. The fundamental physical assumption inherent in the model is that the exchange process is rate-limited by the surface interactions. According to the formulation developed here, this assumption leads to a dependence of the isotopic exchange rate, $R$, which is linear with gas pressure and powder surface area. The temperature dependence of $R$, through such factors as $p, \alpha, v_{t}, \mu$, and $n_{g}$ at a given pressure, is more complicated.

The model is applied to the conditions used in recent experimental measurements of isotopic exchange in the H/D/Pd system [Ref. (1)] and is shown to provide a good description of the experimental data. The computational results indicate that the difference in temporal efficiency of exchange which was observed experimentally can be primarily attributed to the sizeable gas-to-solid phase isotope effect present in this gas-solid system. Furthermore, it is found that, for gas phase atoms colliding with the powder surface, roughly one collision in $10^{7}$ results in isotopic exchange. 


\section{APPENDIX \\ DETAILS OF PITTING PROCEDURE}

As stated earlier, the isotopic exchange probability, $p$, and the bed permeability, $K$, are allowed to vary in fitting the model results to experimental data. These two parameters are, to a large extent, uncoupled and each can be varied independently in obtaining the fit. Adjusting the value of $p$ changes the time-rate-of-change of the $D_{2}, H_{2}$, and $H D$ partial pressure curves shown in Figs. 1 and 2. These time derivatives are a direct measure of the efficiency of the exchange process on the microscopic scale, i.e., on the level of the surface interactions. The relationship between the $p$ and this "intrinsic" exchange efficiency is clearly evident in Eqn. (10) with $k$ given by Eqn. (12). On the other hand, varying the quantity $K$ tends to translate the partial pressure curves in time while leaving their shape unchanged. This quantity directly affects the residence time of the gas flowing through the bed and its value is an indication of whether or not a gas molecule entering the bed in the flowstream will have sufficient time to interact with the powder surface so as to be completely exchanged to the other isotope before exiting the bed. In general, fitting model results to experimental data is carried out by adjusting the value of $p$ so as to match the slopes of the calculated $D_{2}$ and $H_{2}$ partial pressure curves to the respective slopes of the measured curves in the vicinity of the point in time where those curves cross, and then by varying the value of $\mathrm{K}$ until this crossing point occurs at the proper time.

The degree to which the value of $K$ obtained from the model fit agrees with the experimentally measured values, provides a check on the appropriateness of the one-dimensional flow description used in the model. While the value of $K$ from the model calculations is not expected to exactly equal the measured $K$, the two values should be similar. In the present case, the model fit of the D-to-H exchange data shown in Fig. 1 yields $\mathrm{K}=5.6 \times 10^{-8} \mathrm{~cm}^{2}$, while measured values of $K$ reported in Ref. (1) are $K_{H}=5.4 \times 10^{-8} \mathrm{~cm}^{2}$ for the hydrided bed and $\mathrm{K}_{\mathrm{D}}=6.1 \times 10^{-8} \mathrm{~cm}^{2}$ for the deuterided bed. (As stated earlier, the value of $K$ obtained from the model fit of the $D-t o-H$ exchange data is used in the model prediction of the H-to-D exchange experiment.) 


\section{REFERENCES}

1. Foltz G. W., and Melius, C. F., SAND86-8225.

2. Melius, C. F., and Coronado, P. R., Sandia National Laboratories, unpublished studies.

3. Klier, K., Nováková, J., and Jiru, P., J. Catal. 2, 479 (1963). See also, for example, Nováková, J., Catal. Rev. 4, 77 (1970); Nováková, J., Jíru, P., and Zavadil, V., Coll. Czech. Chem. Commun. 36, 520 (1971); Nováková, J., Jirú, P., and Zavadil, V., Coll. Czech. Chem. Commun. 38, 2320 (1973).

4. See, for example, Sicking, G., Ber. Bunsenges. Physik. Chem. 76, 790 (1972).

5. See, for example, Bond, G. C., "Catalysis by Metals," Academic Press, London, 1962.

6. Dullien, F. A. L., "Porous Media, Fluid Transport and Pore Structure," Academic Press, New York, 1979.

7. Bird, R. B., Stewart, W. E., and Lightfoot, E. N., "Transport Phenomena," Wiley, New York, 1960; Reid, R. C., Prausnitz, J. M., and Sherwood, T. K., "The Properties of Gases and Liquids," McGraw-Hi1l, New York, 1977.

8. Glueckauf, E., and Kitt, G. P., in "Vapour Phase Chromatography," (D. H. Desty and C. L. A. Harbourn, Eds.), p.422. Butterworths Scientific Publications, London, 1957.

9. Wicke, E, and Nernst, G. H., Ber. Bunsenges. Phys. Chem. 68, 224 (1964).

10. Botter, F., J. Less-Common Metals 49, 111 (1976).

11. Andreev, B. M., Polevoi, A. S., and Perevezentsev, A. N., Soviet Atomic Energy 45, 710 (1979).

12. Wicke, E., and Brodowsky, H., in "Hydrogen in Metals II" (G. Alefeld and J. Völkl, Eds.), p. 73. Springer-Verlag, Berlin, 1978.

13. Andreev, B. M., Boreskov, G. K., Chang-tsun, C., and Tsionskii, V. M., Kinet. Catal. 7, 416 (1966).

14. Andreev, B. M., Perevezentsev, A. N., and Shitikov, V. V., Russian J. Phys. Chem. 55, 1132 (1981). 


\section{UNLIMITED RELEASE}

Dr. Robert H. Hsu Savannah River Laboratory E. I. Du Pont De Nemours \& Co. Aiken, SC 29808

Dr. Robert H. Sherman Tritium Systems Test Assembly Los Alamos National Laboratory Los Alamos, NM 87545

Professor Wayne L. Worrell

Department of Materials Science \& Engineering

University of Pennsylvania

3231 Walnut Street

Philadelphia, PA 19104

Professor John Yates

Department of Chemistry

University of Pittsburgh

Pittsburgh, PA 15260

20 0. E. Jones

1000 W. F. Brinkman

1100 F. L. Vook

1110 S. T. Picraux

1124 T. D. Raymond

1130 G. A. Samara

1134 D. W. Goodman

1140 P. S. Peercy

1800 R. L. Schwoebel

1823 D. R. Tallant

1840 R. J. Eagan

1841 B. D. Kay

1842 R. E. Loehman

6000 D. L. Hartley

8000 R. S. Claassen

Attn: E. E. Ives, 8100

R. J. Detry, 8200

8244 C. M. Hartwig

8244 B. A. Meyer

8245 R. J. Kee

8300 P. L. Mattern

8310 R. W. Rhode

8312 J. E. Smugeresky

8314 J. E. Costa

8315 D. L. Lindner

8315 B. E. Mills

8315 D. A. Nissen 


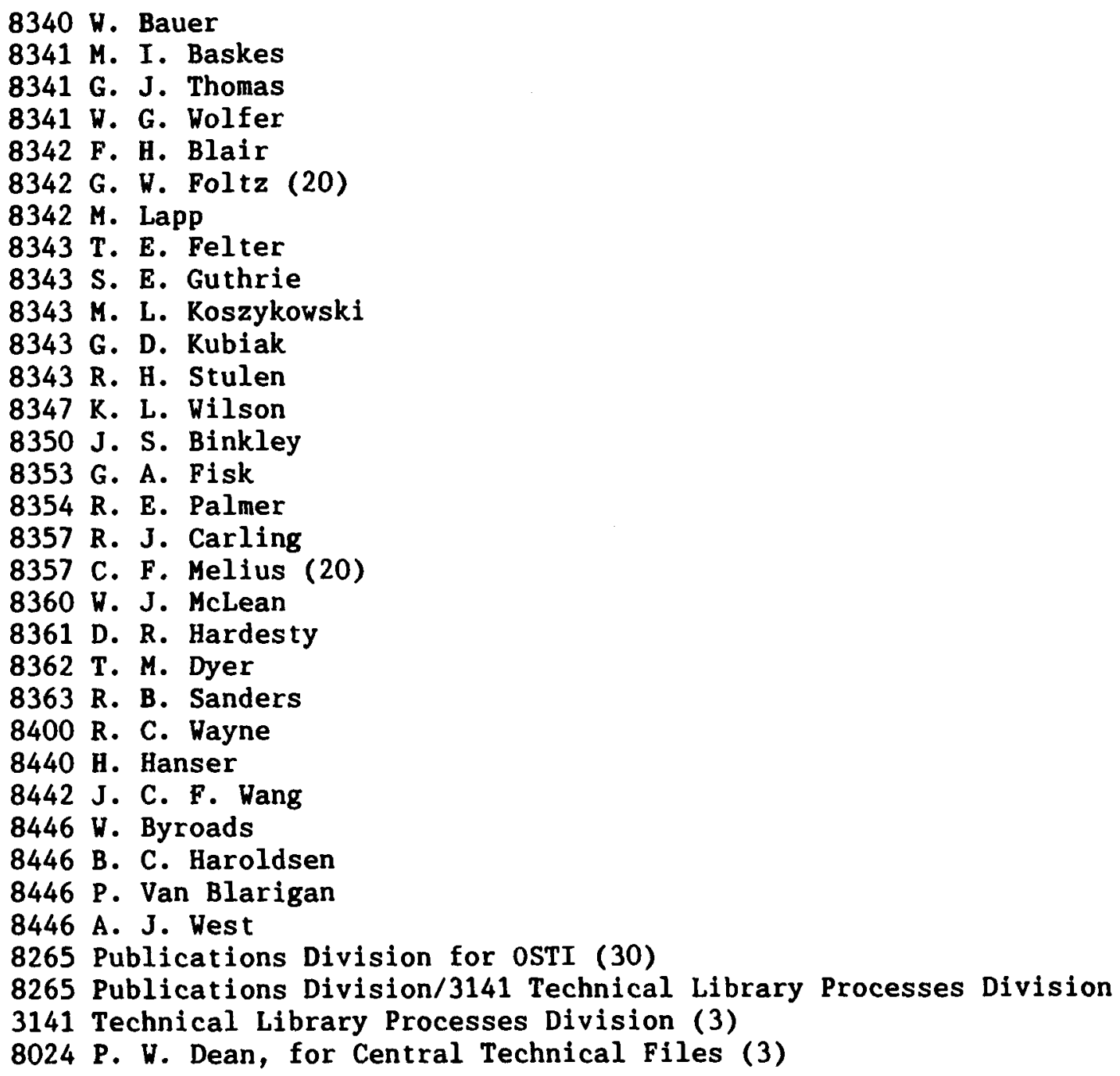

